\title{
Three-Dimensional Silicon Photonic Crystals
}

Shawn-Yu Lin ${ }^{1 *}$, J. G. Fleming ${ }^{1}$, D.L. Hetherington ${ }^{1}$, B.K. Smith ${ }^{1}$, W. Zubrzycki ${ }^{1}$, R. Biswas ${ }^{2}$, M.M. Sigalas ${ }^{2}$, and K.M. $\mathrm{Ho}^{2}$.

${ }^{1}$ Sandia National Laboratories, P.O. Box 5800, Albuquerque, NM 87185

${ }^{2}$ Ames Laboratory, Dept. of Physics and Astronomy, Iowa State University, Ames, IA 50011

Abstract

In this work, we report the realization of a series of silicon 3D photonic crystals operating in the infrared (IR), mid-IR and most importantly the near-IR $(\lambda=1-2 \mu \mathrm{m})$ wavelengths. The structure maintains its crystal symmetry throughout the entire 6 -inches wafer and holds a complete photonic bandgap.

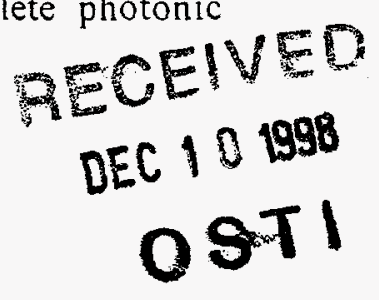

Sandia is a multiprogram laboratory operated by Sandia Corporation, a Lockheed Martin Company, for the United States Department of Energy under Contract DE-AC04-94AL85000.

*All correspondence should be addressed to Dr. Shawn-Yu Lin, 505-844-8097(phone), 505-8448985(fax), slin@sandia.gov(e-mail). 


\section{DISCLAIMER}

This report was prepared as an account of work sponsored by an agency of the United States Government. Neither the United States Government nor any agency thereof, nor any of their employees, make any warranty, express or implied, or assumes any legal liability or responsibility for the accuracy, completeness, or usefulness of any information, apparatus, product, or process disclosed, or represents that its use would not infringe privately owned rights. Reference herein to any specific commercial product, process, or service by trade name, trademark, manufacturer, or otherwise does not necessarily constitute or imply its endorsement, recommendation, or favoring by the United States Government or any agency thereof. The views and opinions of authors expressed herein do not necessarily state or reflect those of the United States Government or any agency thereof. 


\section{DISCLAIMER}

Portions of this document may be illegible in electronic image products. Images are produced from the best available original document. 


\section{Three-Dimensional Silicon Photonic Crystals}

Shawn-Yu Lin ${ }^{1}$, J. G. Fleming ${ }^{1}$, D.L. Hetherington ${ }^{1}$, B.K. Smith ${ }^{1}$, R. Biswas ${ }^{2}$, M.M. Sigalas ${ }^{2}$, and K.M. $\mathrm{Ho}^{2}$.

${ }^{1}$ Sandia National Laboratories, P.O. Box 5800, Albuquerque, NM 87185

${ }^{2}$ Ames Laboratory, Dept. of Physics and Astronomy, Iowa State University, Ames, IA 50011

A three-dimensional (3D) photonic crystal is an optical analogous of a semiconductor that is useful for controlling and manupulating the flow of light on a semiconductor chip. The realization of high efficiency sub- $\mu \mathrm{A}$ edge-emitting-lasers [1], high speed tera-Hertz optical switches and the routing of optical signal in all three-dimensions are but a few benifits of 3D photonic crystals.

In this work [2], we report the realization of a series of silicon 3D photonic crystals operating in the infrared (IR), mid-IR and most importantly the near-IR $(\lambda=1-2 \mu \mathrm{m})$ wavelengths. The structure maintains its crystal symmetry throughout the entire 6-inches wafer and holds a complete photonic bandgap. This demonstration opens the door for si-based photonic crystal devices that is compatible with the well-developed $\mathrm{Si}$ microelectronics processes and is suitable for the large-scale photonic integration.

Our approach takes advantage of two recent breakthroughs. Firstly, a layer-stacking scheme is adopt to construct a 3D crystal for its design simplicity [3-5]. Secondly, a planarization process call Chemical-Mechanical-Polishing is recognized to be the key process for repetitive fabrication of layer structures that constitute the topology of a 3D photonic crystal. With these new approaches, silicon photonic crystal structures were sucessufully fabricated. A scanning-electron-microscopy image of such a layer-by-layer 3D photonic crystal built on silicon substrate is shown in Fig.1(a). The structure has a diamond lattice symmetry.

The transmission spectrum of light propagating along the $<001>$ direction of the $3 \mathrm{D}$ crystal, i.e. normal to the substrate, is shown in Fig.1(b) for both near-IR and IR photonic crystals. In the top panel, a strong transmittance dip is observed at $\lambda=1.35$ to $1.95 \mu \mathrm{m}$ for the near-IR crystal, suggesting the existence of a photonic bandgap in the optical $\lambda$. In the bottom panel, a similar transmission dip was observed at wavelengths $\lambda=10-14.5 \mu \mathrm{m}$ for the IR photonic crystal.

Experimental results taken from a 3-D single mode cavity (with a modal volume of $\sim 1 \lambda^{3}$ ), thermal emissivity data and the modified spontaneous emission spectrum will also be described.

References:

[1] Yablonovitch, E. Phys. Rev. Lett. 55, 2059-2063 (1987).

[2] Lin, S.Y. et al, Nature 394, 251-253 (1998).

[3] Ho, K.M. et al, Solid State Comm. 89, 413 (1994).

[4] Fan, S. et al, Appl. Phys. Lett. 65, 1466 (1994).

[5] Sozuer, H.S. et al, J. Modern Optics 41, 231 (1994). 

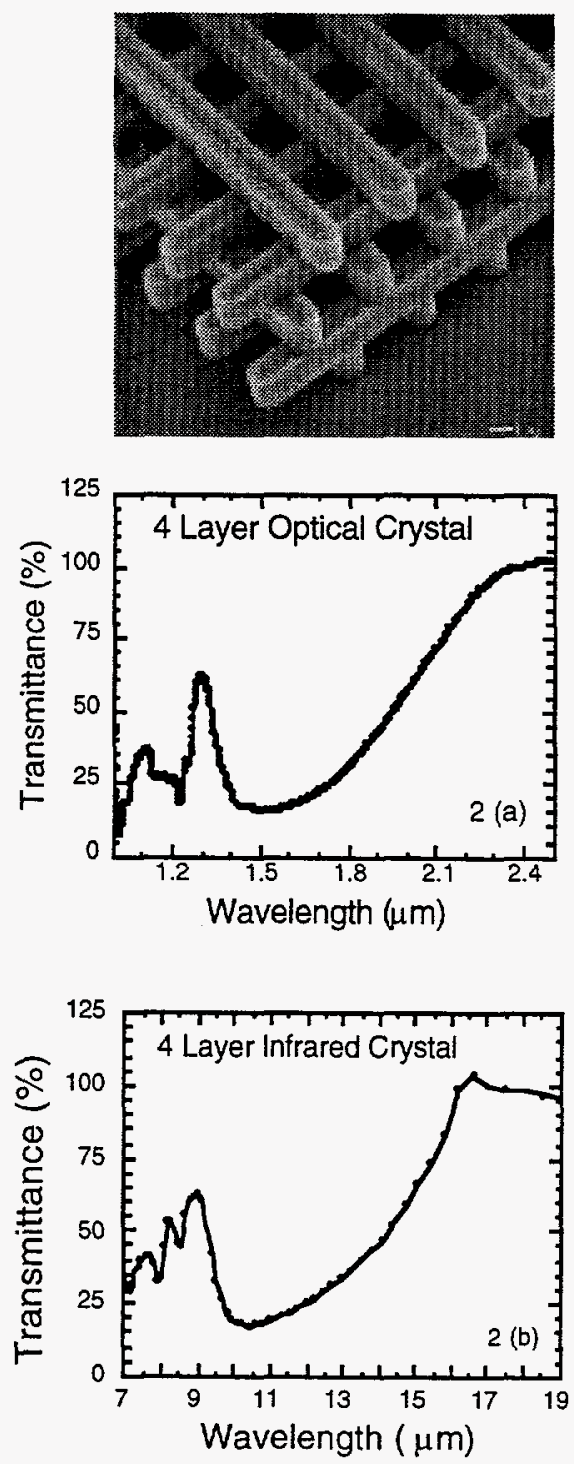
Fig.1 A SEM image of a 5-layer infrared 3D photonic crystal.

Fig.2 (a) Transmission spectrum taken from an optical 3D photonic crystal; 2 (b) spectrum taken from an infrared 3D photonic crystal. 